\title{
The Electrolytic Dissociation of Aryl Derivatives of Succinic Acid
}

\author{
Elene Kvaratskhelia, Rusudan Kurtanidze \\ R. Agladze Institute of Inorganic Chemistry and Electrochemistry, Iv. Javakhishvili Tbilisi State University, Tbilisi, Georgia \\ Email: elicko@mail.ru, ekvarats@yahoo.com
}

How to cite this paper: Kvaratskhelia, E. and Kurtanidze, R. (2017) The Electrolytic Dissociation of Aryl Derivatives of Succinic Acid. J. Biomedical Science and Engineering, 10, 163-171. https://doi.org/10.4236/jbise.2017.104013

Received: March 30, 2017

Accepted: April 27, 2017

Published: April 30, 2017

Copyright (c) 2017 by authors and Scientific Research Publishing Inc. This work is licensed under the Creative Commons Attribution International License (CC BY 4.0).

http://creativecommons.org/licenses/by/4.0/ (c) (i) Open Access

\begin{abstract}
In this work, an analysis of the regularities of the electrolytic dissociation of aryl derivatives of the succinic acid (phenylsuccinic, benzylsuccinic, dibenzylsuccinic and phenyl-2-benzylsuccinic acids) in their dilute (0.0001 - 0.01 mol $\cdot \mathrm{dm}^{-3}$ ) solutions was carried out with the aid of a new method of determination of the dissociation parameters of weak multibasic organic acids with the "overlapping equilibria" effect previously described by authors. Values of the usual and "partial" degrees of dissociation, the concentrations of all anions, hydrogen ions and undissociated acid molecules, the activity coefficients of all charged dissociation products were calculated. Together with the accurate equations, the simple empirical equations for fast approximate determination of the various dissociation parameters were also suggested.
\end{abstract}

\section{Keywords}

Dissociation Constant, Dissociation Degree, Weak Organic Acids, Equations, Dissociation Step

\section{Introduction}

Succinic acid and its various derivatives are widely used in the organic synthesis and polymer industry; participate in the biologically important Krebs cycle. Benzylsuccinic acid was described to be the most potent inhibitor of carboxypeptidase A. It is a by-product analog and is proposed to bind to the active site of carboxypeptidase A via the succinyl carboxyl group and a carbonyl group. It was established that benzylsuccinic acid was bound at a single locus at the active site of carboxypeptidase A. The useful properties of these acids are directly connected with the peculiarities of their electrolytic dissociation.

Previously we described the original method for determination of various dissociation parameters of weak multibasic organic acids with the close values of stepwise dissociation constants (the effect of "overlapping equilibria") [1] [2] [3] 
[4]. This method was widely used for an analysis of various weak organic acids with different basicity in their dilute solutions [5]-[14]. The term of the "partial" degree of dissociation was also suggested [2] and used for a more detailed analysis of the complex equilibria existing in the processes of dissociation of such acids. In this work, our method is applied for the study of the peculiarities of electrolytic dissociation of the aryl derivatives of succinic acid: phenylsuccinic, benzylsuccinic, dibenzylsuccinic and phenyl-2-benzylsuccinic acids in their dilute $\left(0.0001-0.01 \mathrm{~mol} \cdot \mathrm{dm}^{-3}\right)$ solutions.

\section{The Equations}

All acids studied in this work are the vivid examples of weak dibasic organic acids with the "overlapping equilibria" effect. This fact is confirmed by the values of the dissociation constants of these acids presented in Table 1.

The law of dilution equations for weak dibasic organic acid with the effect of “overlapping equilibria" may be expressed as follows [1] [2] [3] [4]:

$$
\begin{gathered}
K_{1}=\frac{c\left(\alpha_{1}^{2}-\alpha_{2}^{2}\right)}{1-\alpha_{1}} F_{1}=\frac{\alpha_{1}^{2}\left[1-\left(\alpha_{2}^{\prime}\right)^{2}\right] c}{1-\alpha_{1}} F_{1}=\frac{x_{1}^{2}-x_{2}^{2}}{c-x_{1}} F_{1} \\
K_{2}=\frac{c \alpha_{2}\left(\alpha_{1}+\alpha_{2}\right)}{\alpha_{1}-\alpha_{2}} F_{2}=\frac{\alpha_{1} \alpha_{2}^{\prime}\left(1+\alpha_{2}^{\prime}\right) c}{1-\alpha_{2}^{\prime}} F_{2}=\frac{x^{2}\left(x_{1}+x_{2}\right)}{x_{1}-x_{2}} F_{2}
\end{gathered}
$$

where $K_{1}$ and $K_{2}$ are the thermodynamic dissociation constants for first and second steps, $\alpha_{1}$ and $\alpha_{2}$ are the usual degrees of dissociation for corresponding steps, $\alpha_{2}^{\prime}$ is the "partial" degree of dissociation for the second step, $x_{1}$ and $x_{2}$ are the contributions of first and second steps to the $\left[\mathrm{H}^{+}\right]$value $\left(\left[\mathrm{H}^{+}\right]=x_{1}+x_{2}\right)$, $c$ is the total (analytical) concentration of acid, $F_{1}$ and $F_{2}$ are the quotients of the activity coefficients:

$$
\begin{gathered}
F_{1}=\frac{f_{\mathrm{H}^{+}} f_{\mathrm{HA}^{-}}}{f_{\mathrm{H}_{2} \mathrm{~A}}} \\
F_{2}=\frac{f_{\mathrm{H}^{+}} f_{\mathrm{A}^{2-}}}{f_{\mathrm{HA}^{-}}}
\end{gathered}
$$

The $\alpha_{1}, \alpha_{2}, \alpha_{2}^{\prime}, x_{1}$ and $x_{2}$ values are connected by the following equation:

$$
\begin{gathered}
\alpha_{2}^{\prime}=\alpha_{2} / \alpha_{1}=x_{2} / x_{1} \\
\alpha_{1}=x_{1} / c \\
\alpha_{2}=x_{2} / c
\end{gathered}
$$

Table 1. The dissociation constants of aryl derivatives of succinic acid.

\begin{tabular}{cccc}
\hline Acid & $K_{1}$ & $K_{2}$ & Reference \\
\hline Phenylsuccinic & $1.6 \times 10^{-4}$ & $2.8 \times 10^{-6}$ & {$[15]$} \\
Benzylsuccinic & $7.75 \times 10^{-}$ & $2.3 \times 10^{-6}$ & {$[15]$} \\
Dibenzylsuccinic & $1.096 \times 10^{-4}$ & $2.19 \times 10^{-7}$ & {$[16]$} \\
Phenyl-2-benzylsuccinic & $2.04 \times 10^{-4}$ & $3.39 \times 10^{-7}$ & {$[15][16]$} \\
\hline
\end{tabular}


The concentrations of hydrogen ions, mono and dianions and undissociated acid molecules can be expressed as follows:

$$
\begin{gathered}
{\left[\mathrm{H}^{+}\right]=c\left(\alpha_{1}+\alpha_{2}\right)=c \alpha_{1}\left(1+\alpha_{2}^{\prime}\right)=x_{1}+x_{2}} \\
{\left[\mathrm{HA}^{-}\right]=c\left(\alpha_{1}-\alpha_{2}\right)=c \alpha_{1}\left(1-\alpha_{2}^{\prime}\right)=x_{1}-x_{2}} \\
{\left[\mathrm{~A}^{2-}\right]=c \alpha_{2}=c \alpha_{1} \alpha_{2}^{\prime}=x_{2}} \\
{\left[\mathrm{H}_{2} \mathrm{~A}\right]=c\left(1-\alpha_{1}\right)=c\left(\frac{\alpha_{2}^{\prime}-\alpha_{2}}{\alpha_{2}^{\prime}}\right)=c-x_{1}}
\end{gathered}
$$

The values of the activity coefficients can be approximated by the DebyeHuckel equation:

$$
\lg f_{i}=-\frac{z_{i}^{2} A \sqrt{I}}{1+a_{i} B \sqrt{I}}
$$

where $a_{i}$ is the cation-anion distance of closest approach, $A$ and $B$ are constants depending on the properties of water at given temperature, $Z_{i}$ is the charge of ion. The ionic strength $I=c\left(\alpha_{1}+2 \alpha_{2}\right)=c \alpha_{1}\left(1+2 \alpha_{2}^{\prime}\right)=x_{1}+2 x_{2}$. The values of $a_{i}, A$ and $B$ at $25^{\circ} \mathrm{C}$ were taken from [17], the $a_{i}$ values for studied acids were estimated according to the data also presented in [17]. The activity coefficient of undissociated acid is assumed to be unity. The values of the dissociation constants presented in Table 1 were used in calculations.

According to the Equations ((1) and (2)), the $\alpha_{1}, \alpha_{2}, \alpha_{2}^{\prime}, x_{1}$ and $x_{2}$ values can be evaluated successively by iterative solution of following equations:

$$
\begin{array}{r}
\alpha_{1}=\frac{1}{2}\left[-\frac{K_{1}}{c F_{1}}+\sqrt{\left(\frac{K_{1}}{c F_{1}}\right)^{2}+4\left(\alpha_{2}^{2}+\frac{K_{1}}{c F_{1}}\right)}\right] \\
\alpha_{2}=\frac{1}{2}\left[-\left(\frac{K_{2}}{c F_{2}}+\alpha_{1}\right)+\sqrt{\left.\left(\frac{K_{2}}{c F_{2}}+\alpha_{1}\right)^{2}+\frac{4 K_{2} \alpha_{1}}{c F_{2}}\right]}\right. \\
\alpha_{2}^{\prime}=\frac{1}{2}\left[-\left(1+\frac{K_{2}}{\alpha_{1} c F_{2}}\right)+\sqrt{\left(1+\frac{K_{2}}{\alpha_{1} c F_{2}}\right)^{2}+\frac{4 K_{2}}{\alpha_{1} c F_{2}}}\right] \\
x_{1}=\frac{1}{2}\left[-\frac{K_{1}}{F_{1}}+\sqrt{\left(\frac{K_{1}}{F_{1}}\right)^{2}+4\left(x_{2}^{2}+\frac{K_{1} c}{F_{1}}\right)}\right] \\
x_{2}=\frac{1}{2}\left[-\left(\frac{K_{2}}{F_{2}}+x_{1}\right)+\sqrt{\left(\frac{K_{2}}{F_{2}}+x_{1}\right)^{2}+\frac{4 K_{2} x_{1}}{F_{2}}}\right]
\end{array}
$$

When the $\left[\mathrm{H}^{+}\right]$value is known, these parameters may be calculated with the aid of the following equations:

$$
\alpha_{1}=\frac{K_{1}+\left[\mathrm{H}^{+}\right] F_{1} \alpha_{2}}{K_{1}+\left[\mathrm{H}^{+}\right] F_{1}}=\frac{K_{1}}{\left[\mathrm{H}^{+}\right] F_{1}\left(1-\alpha_{2}^{\prime}\right)+K_{1}}
$$




$$
\begin{aligned}
& \alpha_{2}=\frac{K_{2} \alpha_{1}}{K_{2}+\left[\mathrm{H}^{+}\right] F_{2}} \\
& \alpha_{2}^{\prime}=\frac{K_{2}}{K_{2}+\left[\mathrm{H}^{+}\right] F_{2}} \\
& x_{1}=\frac{K_{1} c+\left[\mathrm{H}^{+}\right] F_{1} x_{2}}{K_{1}+\left[\mathrm{H}^{+}\right] F_{1}} \\
& x_{2}=\frac{K_{2} x_{1}}{K_{2}+\left[\mathrm{H}^{+}\right] F_{2}}
\end{aligned}
$$

\section{Results and Discussion}

In Tables 2-5, the values of the usual and "partial" degrees of dissociation and $\mathrm{pH}$ for the dilute $\left(0.0001-0.01 \mathrm{~mol} \cdot \mathrm{dm}^{-3}\right)$ solutions of the studied aryl derivatives of succinic acid are presented. The corresponding $X_{1}$ and $X_{2}$ values may be determined with the aid of the Equations ((6) and (7)).

The comparison of the $\alpha_{2}$ and $\alpha_{2}^{\prime}$ values show that the values of the "partial" degree of dissociation (which more correctly characterize the completeness of dissociation at second step) exceed appreciably the values of the usual degree of dissociation (especially in case of the low $K_{1}$ values and higher acid concentrations).

The values of the activity coefficients of hydrogen ions and mono and dianions determined by the Debye-Huckel equation change within the following limits in the acid concentration interval $0.0001-0.01 \mathrm{~mol} \cdot \mathrm{dm}^{-3}: 0.9911-0.9223$ ( $\mathrm{H}^{+}$ion), 0.9909 - 0.9118 (monoanion); 0.9643 - 0.7007 (dianion).

The Equations (8)-(11) give the opportunity to determine the regions of the acid concentration in which the various charged and uncharged forms of acid

\begin{tabular}{|c|c|c|c|c|}
\hline Acid concentration & $\alpha_{1}$ & $\alpha_{2}$ & $\alpha_{2}^{\prime}$ & $\mathrm{pH} \mathrm{mol} \cdot \mathrm{dm}^{-3}$ \\
\hline 0.0001 & 0.7001 & 0.02698 & 0.03854 & 4.143 \\
\hline 0.0002 & 0.5842 & 0.01404 & 0.02403 & 3.928 \\
\hline 0.0004 & 0.4685 & 0.00723 & 0.01543 & 3.727 \\
\hline 0.0006 & 0.4054 & 0.00489 & 0.01206 & 3.616 \\
\hline 0.0008 & 0.3637 & 0.00371 & 0.01019 & 3.540 \\
\hline 0.001 & 0.3334 & 0.00299 & 0.00896 & 3.482 \\
\hline 0.002 & 0.2510 & 0.00153 & 0.00609 & 3.307 \\
\hline 0.004 & 0.1859 & 0.00078 & 0.00421 & 3.140 \\
\hline 0.006 & 0.1551 & 0.00053 & 0.00341 & 3.044 \\
\hline 0.008 & 0.1362 & 0.00040 & 0.00294 & 2.977 \\
\hline 0.01 & 0.1230 & 0.00032 & 0.00263 & 2.925 \\
\hline
\end{tabular}
prevail. The conditions of equality of the concentrations of these particles are:

Table 2. The values of the dissociation parameters for the dilute solutions of methylsuccinic acid at $25^{\circ} \mathrm{C}$. 
Table 3. The values of the dissociation parameters for the dilute solutions of benzylsuccinic acid at $25^{\circ} \mathrm{C}$.

\begin{tabular}{ccccc}
\hline Acid concentration & $\alpha_{1}$ & $\alpha_{2}$ & $\alpha_{2}^{\prime}$ & $\mathrm{pH} \mathrm{mol} \cdot \mathrm{dm}^{-3}$ \\
\hline 0.0001 & 0.5777 & 0.02209 & 0.03824 & 4.226 \\
0.0002 & 0.4619 & 0.01145 & 0.02479 & 4.029 \\
0.0004 & 0.3577 & 0.00588 & 0.01644 & 3.843 \\
0.0006 & 0.3044 & 0.00397 & 0.01305 & 3.739 \\
0.0008 & 0.2704 & 0.00301 & 0.01112 & 3.667 \\
0.001 & 0.2461 & 0.00242 & 0.00984 & 3.612 \\
0.002 & 0.1819 & 0.00124 & 0.00679 & 3.440 \\
0.004 & 0.1330 & 0.00063 & 0.00474 & 3.283 \\
0.006 & 0.1103 & 0.00043 & 0.00386 & 3.190 \\
0.008 & 0.0964 & 0.00032 & 0.00334 & 3.124 \\
0.01 & 0.0869 & 0.00026 & 0.00299 & 3.074 \\
\hline
\end{tabular}

Table 4. The values of the dissociation parameters for the dilute solutions of dibenzylsuccinic acid at $20^{\circ} \mathrm{C}$.

\begin{tabular}{ccccc}
\hline Acid concentration & $\alpha_{1}$ & $\alpha_{2}$ & $\alpha_{2}^{\prime}$ & $\mathrm{pH} \mathrm{mol} \cdot \mathrm{dm}^{-3}$ \\
\hline 0.0001 & 0.6368 & 0.002256 & 0.003543 & 4.198 \\
0.0002 & 0.5193 & 0.001143 & 0.002201 & 3.988 \\
0.0004 & 0.4085 & 0.000579 & 0.001417 & 3.792 \\
0.0006 & 0.3502 & 0.000389 & 0.001110 & 3.684 \\
0.0008 & 0.3124 & 0.000293 & 0.000939 & 3.609 \\
0.001 & 0.2852 & 0.000236 & 0.000826 & 3.553 \\
0.002 & 0.2126 & 0.000120 & 0.000564 & 3.381 \\
0.004 & 0.1563 & 0.000061 & 0.000391 & 3.216 \\
0.006 & 0.1300 & 0.000041 & 0.000318 & 3.121 \\
0.008 & 0.1138 & 0.000031 & 0.000273 & 3.055 \\
0.01 & 0.1027 & 0.000025 & 0.000244 & 3.003 \\
\hline
\end{tabular}

Table 5. The values of the dissociation parameters for the dilute solutions of 2-phenyl2-benzylsuccinic acid at $25^{\circ} \mathrm{C}$.

\begin{tabular}{|c|c|c|c|c|}
\hline Acid concentration & $\alpha_{1}$ & $a_{2}$ & $\alpha_{2}^{\prime}$ & $\mathrm{pH} \mathrm{mol} \cdot \mathrm{dm}^{-3}$ \\
\hline 0.0001 & 0.7382 & 0.003494 & 0.004733 & 4.134 \\
\hline 0.0002 & 0.6258 & 0.001774 & 0.002835 & 3.907 \\
\hline 0.0004 & 0.5087 & 0.000901 & 0.001771 & 3.698 \\
\hline 0.0006 & 0.4432 & 0.000606 & 0.001368 & 3.583 \\
\hline 0.0008 & 0.3993 & 0.000458 & 0.001147 & 3.504 \\
\hline 0.001 & 0.3671 & 0.000368 & 0.001003 & 3.444 \\
\hline 0.002 & 0.2784 & 0.000188 & 0.000674 & 3.265 \\
\hline 0.004 & 0.2074 & 0.000096 & 0.000462 & 3.094 \\
\hline 0.006 & 0.1735 & 0.000065 & 0.000372 & 2.997 \\
\hline 0.008 & 0.1526 & 0.000049 & 0.000324 & 2.929 \\
\hline 0.01 & 0.1379 & 0.000039 & 0.000286 & 2.877 \\
\hline
\end{tabular}




$$
\begin{gathered}
{\left[\mathrm{H}^{+}\right]=\left[\mathrm{H}_{2} \mathrm{~A}\right]: \alpha_{1}=\frac{1-\alpha_{2}}{2}=\frac{1}{\alpha_{2}^{\prime}+2}} \\
c=2 x_{1}+x_{2}=\left[\mathrm{H}^{+}\right]+x \\
{\left[\mathrm{HA}^{-}\right]=\left[\mathrm{H}_{2} \mathrm{~A}\right]: \alpha_{1}=\frac{1+\alpha_{2}}{2}=\frac{1}{2-\alpha_{2}^{\prime}}} \\
c=2 x_{1}-x_{2} \\
{\left[\mathrm{~A}^{2-}\right]=\left[\mathrm{H}_{2} \mathrm{~A}\right]: \alpha_{1}=1-\alpha_{2}=\frac{1}{\alpha_{2}^{\prime}+1}} \\
c=x_{1}+x_{2}=\left[\mathrm{H}^{+}\right] \\
{\left[\mathrm{A}^{2-}\right]=\left[\mathrm{HA}^{-}\right]: \alpha_{1}=2 \alpha_{2}} \\
\alpha_{2}^{\prime}=0.5 \\
x_{1}=2 x_{2}
\end{gathered}
$$

The calculations show that the monoanion concentration exceeds the $\left[\mathrm{H}_{2} \mathrm{~A}\right]$ value when $c \leq 0.0002 \mathrm{~mol} \cdot \mathrm{dm}^{-3}$ (benzyl and dibenzylsuccinic acids), $c \leq 0.0003$ $\mathrm{mol} \cdot \mathrm{dm}^{-3}$ (phenylsuccinic acid) and $c \leq 0.0004 \mathrm{~mol} \cdot \mathrm{dm}^{-3}$ (2-phenyl-2-benzylsuccinic acid). In all these cases the inequalities: $\alpha_{1}>\frac{1+\alpha_{2}}{2}, \alpha_{1}>\frac{1}{2-\alpha_{2}^{\prime}}$ and $c<2 x_{1}-x_{2}$ are fulfilled. The regions of prevailing $\left[\mathrm{H}^{+}\right]$values in comparison with the $\left[\mathrm{H}_{2} \mathrm{~A}\right]$ values are: $c<0.0002 \mathrm{~mol} \cdot \mathrm{dm}^{-3}$ (benzyl and dibenzylsuccinic acids) and $c \leq 0.0004 \mathrm{~mol} \cdot \mathrm{dm}^{-3}$ (phenyl and 2-phenyl-2-benzylsuccinic acid). In all these cases, the inequalities $\alpha_{1}>\frac{1-\alpha_{2}}{2}, \alpha_{1}>\frac{1}{2+\alpha_{2}^{\prime}}$ and $c<2 x_{1}+x_{2}$ are fulfilled.

\section{The Empirical Equations}

In conclusion, taking into account the comparatively complexity of the calculations with the aid of the Equations (13)-(22), we suggest also the simple empirical equations for fast approximate determination of the values of usual and "partial" degrees of dissociation and $\mathrm{pH}$ in the dilute solutions of all studied derivatives of succinic acid.

Phenylsuccinic acid

$$
\alpha_{1}=0.036817 c^{-0.322}
$$

(up to $c=0.001 \mathrm{~mol} \cdot \mathrm{dm}^{-3}$ )

$$
\alpha_{2}=4.093 \times 10^{-6} c^{-0.955}
$$

(up to $c=0.01 \mathrm{~mol} \cdot \mathrm{dm}^{-3}$ )

$$
\alpha_{2}^{\prime}=1.1117 \times 10^{-4} c^{-0.633}
$$

(up to $c=0.002 \mathrm{~mol} \cdot \mathrm{dm}^{-3}$ )

$$
\mathrm{pH}=1.515-0.654 \lg c
$$

(up to $c=0.01 \mathrm{~mol} \cdot \mathrm{dm}^{-3}$ ) 
Benzylsuccinic acid

$$
\alpha_{1}=0.019588 c^{-0.367}
$$

(up to $c=0.002 \mathrm{~mol} \cdot \mathrm{dm}^{-3}$ )

$$
\alpha_{2}=3.221 \times 10^{-6} c^{-0.959}
$$

(up to $c=0.01 \mathrm{~mol} \cdot \mathrm{dm}^{-3}$ )

$$
\alpha_{2}^{\prime}=1.6444 \times 10^{-4} c^{-0.592}
$$

(up to $c=0.002 \mathrm{~mol} \cdot \mathrm{dm}^{-3}$ )

$$
\mathrm{pH}=1.778-0.61 \lg c
$$

(up to $c=0.01 \mathrm{~mol} \cdot \mathrm{dm}^{-3}$ )

Dibenzylsuccinic acid

$$
\alpha_{1}=\lg \left(0.16558 c^{-0.353}\right)
$$

(up to $c=0.001 \mathrm{~mol} \cdot \mathrm{dm}^{-3}$ )

$$
\alpha_{2}=2.68534 \times 10^{-7} c^{-0.981}
$$

(up to $c=0.01 \mathrm{~mol} \cdot \mathrm{dm}^{-3}$ )

$$
\alpha_{2}^{\prime}=1.01158 \times 10^{-5} c^{-0.634}
$$

(up to $c=0.001 \mathrm{~mol} \cdot \mathrm{dm}^{-3}$ )

$$
\mathrm{pH}=1.609-0.645 \lg c
$$

(up to $c=0.01 \mathrm{~mol} \cdot \mathrm{dm}^{-3}$ )

\section{2-Phenyl-2-benzylsuccinic acid}

$$
\alpha_{1}=\lg \left(0.17947 c^{-0.37}\right)
$$

(up to $c=0.001 \mathrm{~mol} \cdot \mathrm{dm}^{-3}$ )

$$
\alpha_{2}=4.31519 \times 10^{-7} c^{-0.977}
$$

(up to $c=0.01 \mathrm{~mol} \cdot \mathrm{dm}^{-3}$ )

$$
\alpha_{2}^{\prime}=9.37562 \times 10^{-6} c^{-0.673}
$$

(up to $c=0.001 \mathrm{~mol} \cdot \mathrm{dm}^{-3}$ )

$$
\mathrm{pH}=1.366-0.69 \lg c
$$

(up to $c=0.01 \mathrm{~mol} \cdot \mathrm{dm}^{-3}$ )

For all described empirical equations the values of the relative error do not exceed 5\% - 7\% (the relative error is the ratio of the difference between the approximate and accurate values, divided by the approximate value, and converted to percent).

In [18], we considered also the possibility of obtaining of the general empirical equations for $\alpha_{1}, \alpha_{2}$ and $\mathrm{pH}$ values in which these parameters were connected with the dissociation constants and acid concentration. Such equations were obtained as a result of the investigation of dependence of the constants of empirical equations on the dissociation constants values of various weak dibasic organic acids. 
For the $\alpha_{1}$ value we suggest two general empirical equations. The first equation corresponds to the $p K_{1}$ values range 2.5 - 3.75:

$$
\alpha_{1}=2.696-0.957 p K_{1}-0.5058 \times 10^{-8.257 \sqrt{K_{1}}} \lg c
$$

For the $p K_{1}$ values range 3.8 - 4.7, we suggest the following equation:

$$
\alpha_{1}=-2.122+0.338 p K_{1}-\left(1.025-0.17 p K_{1}\right) \lg c
$$

The $p K_{1}$ values of the studied in this work derivatives of succinic acid are within the range 3.54 - 3.69 (2-phenyl-2-benzylsuccinic acid) and $3.77-4.13$ (phenyl, benzyl and dibenzylsuccinic acids). Consequently, corresponding calculations were carried out using both general Equations (48) and (49). Our calculations show that Equations ((48) and (49)) can be used (taking into account the $p K_{1}$ values) in the following concentration interval: $c=0.0001-0.01$ $\mathrm{mol} \cdot \mathrm{dm}^{-3}$.

For the $\mathrm{pH}$ values of the dilute solutions of the aryl derivatives of succinic acid can be used suggested by us following general empirical equation:

$$
\mathrm{pH}=-1.489+0.8 p K_{1}-\left(1.185-0.14 p K_{1}\right) \lg c
$$

This equation may be used in all studied interval of the acid concentration. For all acids the values of relative error in this interval do not exceed $5 \%$.

For the $\alpha_{2}$ value we suggest the following general empirical equation:

$$
\alpha_{2}=337 K_{2}^{1.426+m \lg c}
$$

where $m$ values for studied acids are within the range $0.16603-0.17954$. This equation may be used in the concentration interval $c=0.0001-0.001 \mathrm{~mol} \cdot \mathrm{dm}^{-3}$ (dibenzyl and 2-phenyl-2-benzyl derivatives) and in all studied concentration interval in case of phenyl and benzyl derivatives. In all these cases the values of the relative error do not exceed $14 \%$.

\section{Conclusion}

With the aid of the method previously described by the authors, an analysis of the regularities of electrolytic dissociation of the aryl derivatives of succinic acid: phenylsuccinic, benzylsuccinic, dibenzylsuccinic and phenyl-2-benzylsuccinic acids was carried out. Values of the degrees of dissociation of both steps, the "partial" degrees of dissociation of second step, concentrations of hydrogen ion, monoanion and dianion and undissociated acid were determined for the dilute $\left(0.0001-0.01 \mathrm{~mol} \cdot \mathrm{dm}^{-3}\right)$ solutions of above mentioned acids. The concentration intervals of domination of various charged and uncharged forms of these acids were established. Simple empirical equations were suggested for the fast approximate calculation of $\alpha_{1}, \alpha_{2}, \alpha_{2}^{\prime}$ and $\mathrm{pH}$ values for all studied acids.

\section{References}

[1] Kvaratskhelia, E. and Kvaratskhelia, R. (2007) The Degrees of Dissociation of Weak Multibasic Organic Acids. Journal of Solution Chemistry, 36, 787-792. https://doi.org/10.1007/s10953-007-9147-0

[2] Kvaratskhelia, E. and Kvaratskhelia, R. (2009) The "Partial" Degrees of Dissociation 
of Weak Multibasic Organic Acids. Journal of Solution Chemistry, 38, 345-349. https://doi.org/10.1007/s10953-009-9377-4

[3] Kvaratskhelia, E. and Kvaratskhelia, R. (2009) The Forms of the Law of Dilution for Weak Multibasic Organic Acids in Case of Overlapping Equilibria. ECS Transactions, 16, 49-54. https://doi.org/10.1149/1.3103809

[4] Kvaratskhelia, E. and Kvaratskhelia, R. (2010) The Determination of Acidity of the Dilute Solutions of Weak Multibasic Organic Acids. Journal of Biomedical Science and Engineering, 3, 484-487. https://doi.org/10.4236/jbise.2010.35067

[5] Kvaratskhelia, E. and Kvaratskhelia, R. (2008) The Electrolytic Dissociation of Mellitic Acid. Journal of Solution Chemistry, 37, 1063-1070. https://doi.org/10.1007/s10953-008-9292-0

[6] Kvaratskhelia, R.K. and Kvaratskhelia, E.R. (2008) Electrochemical Behavior of Tartaric Acid at Solid Electrodes in Aqueous and Mixed Solutions. Russian Journal of Electrochemistry, 44, 230-233. https://doi.org/10.1134/S1023193508020110

[7] Kvaratskhelia, R.K. and Kvaratskhelia, E.R. (2009) On Dissociation of Weak Dibasic and Tribasic Organic Acids Participating in Krebs cycle. Russian Journal of Electrochemistry, 45, 221-224. https://doi.org/10.1134/S1023193509020141

[8] Kvaratskhelia, R.K. and Kvaratskhelia, E.R. (2010) Regularities of Electrolytic Dissociation of Oxalic Acid Homologues. Russian Journal of Electrochemistry, 46, 952956. https://doi.org/10.1134/S1023193510080148

[9] Kvaratskhelia, E. and Kvaratskhelia, R. (2010) The Electrolytic Dissociation of Benzenetricarboxylic Acids. In: Burley, K.T., Ed., Physical Organic Chemistry: New Developments, Nova Science Publishers, New York, 171-182.

[10] Kvaratskhelia, E. and Kvaratskhelia, R. (2011) The Electrolytic Dissociation of Benzenetetra and Benzenepentacarboxylic Acids. In: Taylor, J.C., Ed., Advances in Chemistry Research, Vol. 10, Nova Science Publishers, New York, 409-428.

[11] Kvaratskhelia, E. and Kvaratskhelia, R. (2010) The Regularities of Electrolytic Dissociation of Mesaconic and Itaconic Acids. ECS Transactions, 25, 1-5.

[12] Kvaratskhelia, E. and Kvaratskhelia, R. (2010) The Electrolytic Dissociation of 1,1Cyclopropanedicarboxylic and 1,1-Cyclobutanedicarboxylic Acids. ECS Transactions, 28, 1-4. https://doi.org/10.1149/1.3490117

[13] Kvaratskhelia, E. and Kvaratskhelia, R. (2011) The Regularities of Electrolytic Disso-ciation of 1,2-Cyclopropanedicarboxylic Acids. ECS Transactions, 35, 1-6. https://doi.org/10.1149/1.3646092

[14] Kvaratskhelia, E. and Kvaratskhelia, R. (2012) The Electrolytic Dissociation of 1,2Cyclobutanedicarboxylic Acids. ECS Transactions, 41, 1-5. https://doi.org/10.1149/1.4703916

[15] Dobos, D. (1980) Electrochemical Data. Akademiai Kiado, Budapest.

[16] Dean, J.A. (1999) Lange's Handbook of Chemistry. 15th Edition, McGraw-Hill, Inc., New York, St. Louis, San Francisco.

[17] Koryta, J., Dvorak, J. and Kavan, L. (1993) Principles of Electrochemistry. 2nd Edition, Wiley and Sons, Chichester, New York, Brisbane, Toronto, Singapore.

[18] Kvaratskhelia, E. and Kvaratskhelia, R. (2011) The Equations for Approximate Calcu-lation of the Dissociation Parameters of Weak Dibasic Organic Acids. Bulletin of the Georgian National Academy of Sciences, 5, 65-68. 
Submit or recommend next manuscript to SCIRP and we will provide best service for you:

Accepting pre-submission inquiries through Email, Facebook, LinkedIn, Twitter, etc. A wide selection of journals (inclusive of 9 subjects, more than 200 journals)

Providing 24-hour high-quality service

User-friendly online submission system

Fair and swift peer-review system

Efficient typesetting and proofreading procedure

Display of the result of downloads and visits, as well as the number of cited articles Maximum dissemination of your research work

Submit your manuscript at: http://papersubmission.scirp.org/

Or contact jbise@scirp.org 